\title{
Suppression of the rat's locomotor activity at low intensities of electric footshock
}

\author{
FRED A. MASTERSON \\ University of Delaware, Newark, Delaware 19711
}

\begin{abstract}
Over $50 \%$ of all just noticeably different footshock intensities lie below $.3 \mathrm{~mA}$ for rats. Unfortunately, the suppression of the rat's locomotor activity by low-intensity footshock precludes the use of these shock intensities in active escape or avoidance training. This activity-suppression effect was demonstrated in an alley and in a tilt cage. One explanation of this effect is that rats remain relatively immobile in order to avoid painful peaks in current density that occur when the animals' paws make or break contact with "hot" grids. If this explanation is correct, the activity-suppression effect should be more pronounced with higher impedance shock sources. Some evidence is reported that is consistent with this explanation.
\end{abstract}

Electric footshock remains by far the most widely used stimulus for producing measured amounts of discomfort in unrestrained animals. This is because footshock is easier to control than, for example, loud noise, bright light, air blasts, and hot and cold temperatures, and its motivational potency does not habituate over time (Masterson, 1965, 1969).

Since over $50 \%$ of all just aversively different shocks fall below $.3 \mathrm{~mA}$ for the rat ( Masterson, in press; Masterson \& Campbell, 1972), it is natural to inquire why these intensities are infrequently used in studies of rat escape and avoidance behavior. Approximately 26 just aversive differences (JADs) range between the shock aversion threshold $(.041 \mathrm{~mA})$ and the $5 \%$-tetanization threshold $(3.8 \mathrm{~mA}$, at which $5 \%$ of rat subjects display symptoms of tetany). Of these $26 \mathrm{JADs}, 15$, or over $50 \%$, fall below $.3 \mathrm{~mA}$. Yet, with few exceptions (e.g., Kimble, 1955; Levine, 1966), studies of escape and avoidance have not used intensities below $.3 \mathrm{~mA}$.

A plausible explanation for the relative absence of low shock intensities is that, while low-intensity shocks are highly discriminable in terms of aversiveness, the absolute intensities of aversiveness usually are not sufficiently high to motivate active escape or avoidance responses, such as barpressing or runway traversal. Indeed, the shock aversion threshold, above which one begins to count successive JADs, is deceptively low due to the sensitivity of the technique by which it is measured. Specifically, Campbell and Masterson (1969) used a spatial preference situation in which rats could choose between shock and no shock by standing on one side or the other of a rectangular grid-floor chamber. The crucial factor is that the rats could avoid shock $100 \%$ of the time merely by standing or sitting on the nonshock side: a passive, low-energy response. While rats will

Reprint requests should be sent to Fred A. Masterson, Department of Psychology, University of Delaware, Newark Delaware 19711. move to one side of a box to get away from shock, they may not be sufficiently motivated to repeatedly perform an active, higher energy response to keep away from the shock. Higher shock intensities (e.g., $.5 \mathrm{~mA}$ or larger) may be necessary to motivate active responses on a repeated basis.

Informal observations convinced us that there is another reason that rats will not repeat a large-scale active response to escape or avoid low-level shocks: Low-intensity footshock causes rats to inhibit or curtail large-scale activity (LSA). In a study of runway avoidance, Masterson (1965) observed erratic performance below intensities equivalent to $.3 \mathrm{~mA}$ (I mean "equivalent" in the sense of the equal-aversion functions derived by Campbell \& Masterson, 1969). This inferior performance was due to the failure of some of the rats to traverse the runway. Instead, these rats stayed in the startbox, in which they performed flinching responses, characterized by movements of parts of the body with little or no change in the position of the rat's body. The flinching responses and continuous vocalization of these rats demonstrated their discomfort; yet, they would not move to get away from the shock. Similarly, Masterson (1970) was unable to shape barpress escape responding with shock intensities below the equivalent of $.3 \mathrm{~mA}$. The rats evidenced distress at lower intensities, but they refrained from LSA, making it impossible to shape a bar-approach response. Instead, the rats performed the flinching responses observed in the earlier experiment.

Kimble (1955) studied the effects of shock intensity on the frequencies of flinching and jumping responses. He defined flinching as a startle movement of the body without the paws' leaving the grid floor. Kimble found that flinching predominated at current intensities below $.3 \mathrm{~mA}$. Indeed, jumping rarely occurred at these low intensities. However, the incidence of jumping, a form of LSA, rose sharply at $.3 \mathrm{~mA}$, at which intensity it matched the incidence of flinching. Above $.3 \mathrm{~mA}$, flinching decreased and jumping increased until, at intensities 
above $.5 \mathrm{~mA}$, jumping occurred on nearly every trial, whereas flinching never occurred. In terms of the present hypothesis, $.3 \mathrm{~mA}$ marked the point, as shock intensity increased, at which LSA suppression, as evidenced by flinching, gave way to LSA production, as evidenced by jumping.

\section{EXPERIMENT 1}

The purpose of the first experiment was to obtain an objective measure of the LSA-suppression effect observed informally on previous occasions.

\section{Method}

Subjects. The 30 90- to 110 -day-old male Wistar rats were assigned to six equal-sized groups. The rats were maintained in individual cages with ad-lib access to water and Purina chow blocks.

Apparatus. The apparatus consisted of a 152-cm-long $x$ $12.5-\mathrm{cm}$-wide $\times 20.5-\mathrm{cm}$-high runway section with aluminum walls, Plexiglas top, and a floor of $2.38-\mathrm{mm}$ stainless steel shock grids placed $12.7 \mathrm{~mm}$ apart, center to center. A row of lamps $85 \mathrm{~cm}$ above the runway produced an illumination of $.5 \mathrm{fc}$ at the grids. Electric shock was provided by a 150-kohm fixedimpedance ac source, and the shock grid polarity pattern was scrambled twice per second using a stepping switch (Masterson \& Campbell, 1972).

Procedure. Each group of rats experienced a different shock intensity. The intensities were $0,20,30,45,68$, and $100 \mathrm{~V}$ (which are equal in aversiveness to .00-, .029-, .054-, .102-, $.194-$, and .353-mA shocks from a $500-\mathrm{V}$ constant-current ac source; Campbell \& Masterson, 1969). Each rat was allowed to explore the runway for $5 \mathrm{~min}$ without shock. After that, a rat received a 6-min exposure to the shock, during which LSA was measured. LSA was defined as follows. Five strips of black tape were placed on the Plexiglas lid at $29.2-\mathrm{cm}$ intervals. From a perch on a stool above the runway, the experimenter could count the number of times the rat's body intersected a different tape strip. Once a strip had been intersected, a fresh count was recorded only when the rat intersected one of the adjacent strips. In other words, a rat could not increase the count by merely moving back and forth under a single strip.

\section{Results and Discussion}

The results are shown in Figure 1. The curve for the first 2-min block of the 6-min session shows a relatively constant LSA value from 0 through $68 \mathrm{~V}$ and a large increase at $100 \mathrm{~V}$. The curve for the second 2-min block shows a continuous decrease in LSA from 0 to $68 \mathrm{~V}$, followed by an increase from $68 \mathrm{~V}$ to $100 \mathrm{~V}$. The results for the third 2-min block are identical to those of the second, suggesting that this is a stable or asymptotic pattern.

An analysis of variance performed on the asymptotic data (LSA summed over the last $4 \mathrm{~min}$ ) revealed significant differences between the shock intensities $[F(5,24)$ $=4.2, \mathrm{p}<.01]$. A Newman-Keuls test revealed that the 68-V LSA was reliably $(p=.05)$ lower than the LSA measured at 0,20 , and $100 \mathrm{~V}$ and, also, that the LSA measured at $30 \mathrm{~V}$ was reliably lower than that observed at $20 \mathrm{~V}$. A trend analysis revealed a significant quadratic trend $[F(1,24)=6.75, p<.05]$ and significant higher order trends $[F(3,24)=3.39, p<.05]$, but no signifi-

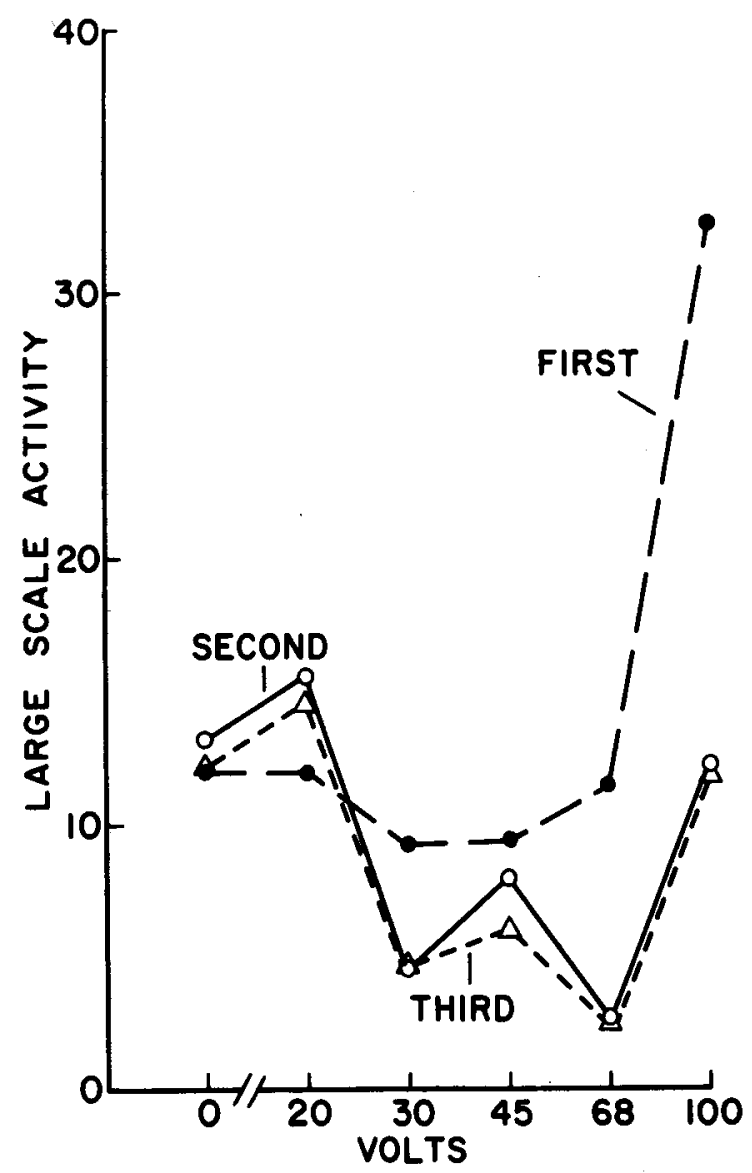

Figure 1. The rat's large-scale activity in a runway as a function of shock intensity. The data are plotted in successive 2-min blocks.

cant linear trend $[F(1,24)=3.65, p>.05]$. The quadratic trend accounted for $32.8 \%$ of the between-group variance, and higher order trends accounted for $49.5 \%$. The nonsignificant linear trend accounted for $17.7 \%$ of the between-group variance.

Thus, LSA is a U-shaped function of shock activity, with minimal activity occurring in the vicinity of $68 \mathrm{~V}$. These results confirm our earlier, informal observations that rats suppress LSA at low shock intensities.

These data indicate that $100 \mathrm{~V}$ marks the transition from LSA suppression, at lower intensities, to the production of LSA equal to or in excess of the no-shock baseline. In terms of aversiveness, $100 \mathrm{~V}$ from the $150-\mathrm{kohm}$ source corresponds to $.353 \mathrm{~mA}$, which is close to the current intensity in Kimble's (1955) experiment at which small-scale flinching responses gave way to large-scale jumping responses.

\section{EXPERIMENT 2}

How can the U-shaped profile obtained for LSA in Experiment 1 be reconciled with Campbell and Masterson's (1969) tilt-cage activity data, in which activity is a continuously increasing function of shock intensity, even at low levels? Tilt-cage activity appears to 
be sensitive to small-scale activity (SSA): small movements such as startle reactions or, when a rat is directly over the central pivot line, the redistribution of weight over the four paws. Conceivably, SSA is an increasing function of shock intensity, whereas LSA is a U-shaped function. The purpose of Experiment 2 was to simultaneously measure LSA and SSA as a function of shock intensity in a tilt-cage apparatus similar to that used by Campbell and Masterson.

\section{Method}

Subjects. The 60 rats were similar to, and housed in the same way as, the rats of Experiment 1.

Apparatus. The tilt cage was a $36-\mathrm{cm}$ tong $\times 17-\mathrm{cm}$-wide $x$ 19.5-cm-high box with aluminum walls, Plexiglas roof, and grid floor. Grid geometry was the same as that in Experiment 1. The grid floor was mounted on a central axle perpendicular to the length of the box, so that changes in a subject's position caused the floor to tilt slightly, activating a mercury switch. The tilt cage was mounted in a sound-isolation chamber. A window in the top of the chamber permitted observation. Indirect illumination produced an illumination level at the grids of $.5 \mathrm{fc}$. The shock system was the same as that used in Experiment 1 .

Procedure. Each group of 10 rats experienced a different shock intensity. The intensities studied were $0,30,45,68$, 100 , and $150 \mathrm{~V}$ (equivalent to $.00, .054, .102, .194, .353$, and $.665 \mathrm{~mA}$ delivered from a $500-\mathrm{V}$ constant-current source; Campbell \& Masterson, 1969). Each rat was allowed to explore the tilt cage for $5 \mathrm{~min}$ without shock. After that, a rat received

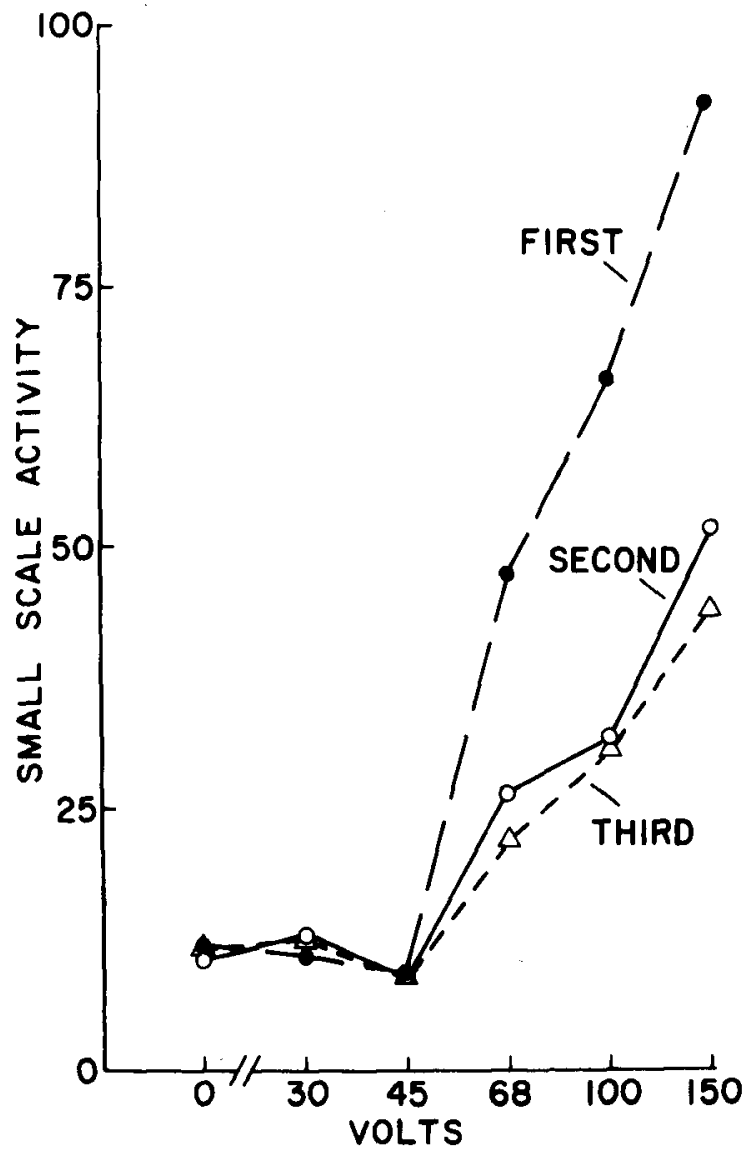

a 6-min exposure to the shock, during which SSA and LSA scores were taken. SSA was measured in terms of floor tilts. LSA was measured by means of two strips of black tape located $8 \mathrm{~cm}$ from each end of the tilt cage and $20 \mathrm{~cm}$ from each other. As in Experiment 1, the experimenter recorded the number of times the rat's body intersected a different tape. (The spacing between the tapes was less than that used in the runway due to the smaller size of the Campbell-Masterson tilt cage. Had the same spacing been used, the tapes would have been too close to the end walls.)

\section{Results and Discussion}

Figure 2a shows that SSA, as measured by floor tilts, is an increasing function of shock intensity, in agreement with Campbell and Masterson (1969). However, Figure 2b shows that simultaneously recorded LSA is a U-shaped function of shock intensity, just as it was in Experiment 1 . Hence there is no contradiction between Experiment 1 and Campbell and Masterson (1969); rather, it appears that SSA and LSA obey different functions.

As in Experiment 1, the activity functions achieved their asymptotic form after $2 \mathrm{~min}$. An analysis of variance performed on the SSA data summed over the last $4 \mathrm{~min}$ revealed significant differences between the shock intensities $[F(5,42)=7.31, p<.01]$. NewmanKeuls comparisons $(p=.05)$ showed that the $150-\mathrm{V}$ SSA was reliably higher than the SSA at all other volt-

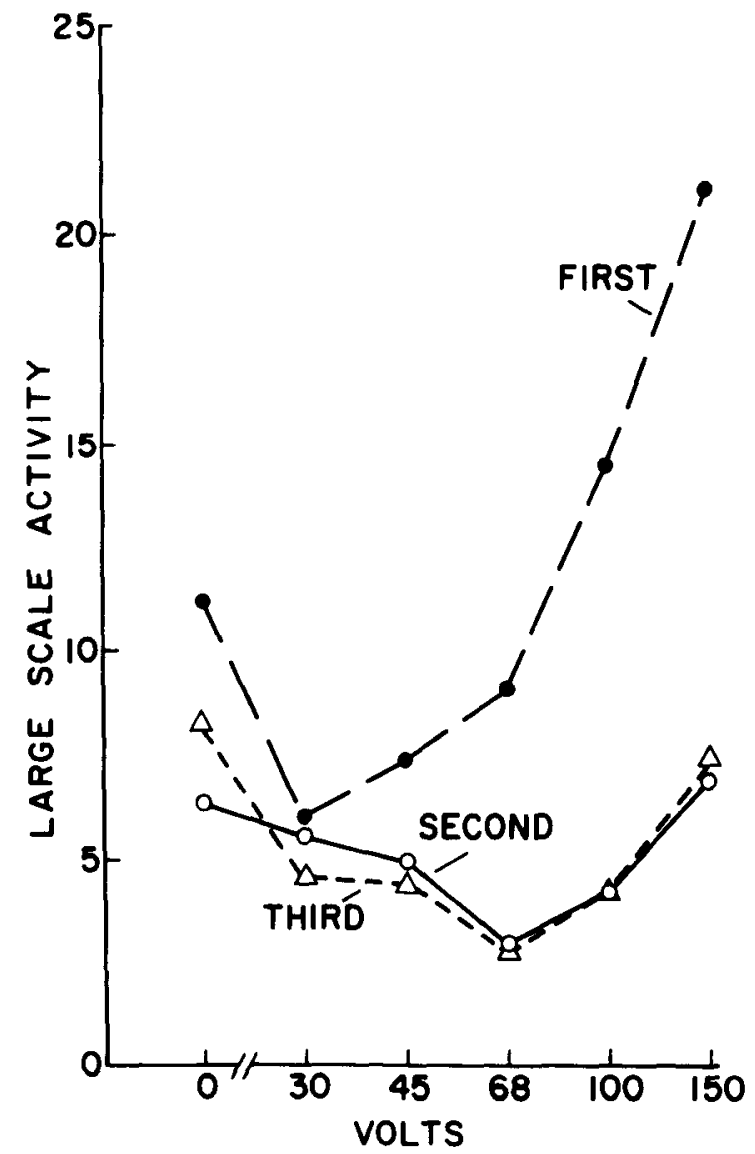

Figure 2. (a) The rat's small-scale activity in a tilt cage as a function of shock intensity. The data are plotted in successive 2-min blocks. (b) The rat's large-scale activity in a tilt cage as a function of shock intensity. The data are plotted in successive 2-min blocks. 
ages and that the 100-V SSA was reliably higher than the SSA at 30 and $45 \mathrm{~V}$. A trend analysis revealed a significant linear trend $[F(1,42)=28.82, p<.01]$, a significant quadratic trend $[F(1,42)=6.66, p<.05]$, and no significant higher order trends $[F(3,42)=.36$, $\mathrm{p}>.05]$. The linear trend accounted for $78.8 \%$ of the between-group variance, and the quadratic trend accounted for an additional $18.2 \%$. The nonsignificant higher order trends accounted for $3.0 \%$ of the betweengroup variance.

An analysis of variance performed on the LSA data summed over the last 4 min revealed significant differences between the shock intensities $[\mathrm{F}(5,42)=5.67$, $\mathrm{p}<.01]$. Newman-Keuls comparisons revealed that the 68.V LSA was significantly lower than both the $0 . \mathrm{V}$ and the 150-V LSA $(p<.05)$. A trend analysis revealed a significant quadratic trend $[F(1,42)=24.27, p<.01]$, no significant linear trend $[\mathrm{F}(1,42)=1.84, \mathrm{p}>.05]$, and no significant higher order trends $[\mathrm{F}(3,42)=.74$, $p>.05]$. The quadratic trend accounted for $85.6 \%$ of the between-group variance. The nonsignificant linear trend accounted for $6.5 \%$ of the between-group variance, and the nonsignificant higher order trends accounted for $7.9 \%$.

That SSA and LSA obey different intensity functions is consistent with our previous, informal observations. Whereas low intensities of footshock were observed to suppress significant changes in body location, they did not discourage small motor reactions, such as flinching reactions. As mentioned earlier, SSA, as measured by floor tilts, appears to be sensitive to these responses.

The absolute amounts of LSA observed in the tilt cage tended to be smaller than those observed in the runway, at least for the zero-intensity conditions. It seems likely that the larger size of the runway encouraged more investigatory behavior, including more large-scale locomotory responses.

\section{EXPERIMENT 3}

The fact that the U-shaped function relating LSA to shock intensity requires 1 or $2 \mathrm{~min}$ to stablize is consistent with the hypothesis that rats learn to minimize their LSA as the result of exposure to low-intensity shocks. The reward for such learning may be the avoidance of abnormally large peaks in current density (Campbell \& Masterson, 1969). When a rat moves over the grids, its paws repeatedly make and break electrical contact. Either when a rat touches a paw to a "hot" grid or when it retracts the paw, a transition point occurs, during which the paw is in minimal contact. At that point, if the other three paws contact oppositepolarity grids, a significant quantity of current may be forced through the minimal contact area. It is likely that concentration of current into such a small area is more painful than the same current spread over the entire paw. Consequently, animals may learn to avoid these peaks in current density by remaining relatively immobile on the grids.

If the LSA suppression observed at low shock intensities is due to the avoidance of current-density peaks, why does the suppression disappear at higher intensities? A simple explanation is that higher intensity shocks elicit reflexive LSA, which is difficult for an animal to voluntarily suppress. In general, footshock causes an excitation of the muscles employed in running and jumping. At low shock intensities, the resulting muscle contractions are small and hence easily confined to flinching responses that avoid current density peaks by maintaining paw contact with the grids. However, at higher intensities, the muscle contractions are larger, making it more difficult for the animal to maintain paw contact. As shock increases, an intensity will be reached at which the effort required to maintain paw contact exceeds, in aversiveness, the incremental discomfort produced by breaking paw contact. At this transitional intensity, the animal will cease to suppress LSA and will run and jump instead.

What determines this intensity marking the transition from LSA suppression to LSA production? One factor is the size of the current-density peaks produced when the animal is in minimal paw contact with the grids. If a shock source can produce large peaks, rats should persist in suppressing LSA even at fairly high intensities, because the effort required to suppress LSA will be adequately compensated by the avoidance of the large current-density peaks produced by LSA. In contrast, if a shock source lacks the capacity to produce large current-density peaks, rats should stop suppressing LSA at a relatively low intensity, since, above this low intensity, the effort expended to inhibit LSA will be more aversive than the incremental discomfort produced by relatively small current-density peaks.

The purpose of Experiment 3 is to measure the LSA suppression produced by equivalent intensities of shock delivered from four shock sources. The sources differ in their ability to maintain high current intensities through high-resistance loads and, hence, to produce currentdensity peaks during times of minimal paw contact.

\section{Method}

Subjects. The 32 subjects were similar to, and housed in the same way as, those of Experiment 1.

Apparatus. The runway apparatus consisted of a $152-\mathrm{cm}-$ long $x$ 12.5-cm-wide $\times 20.5-\mathrm{cm}$-high straight alley and two $30-\mathrm{cm}-\mathrm{long}$ $\times 12.5$-cm-wide $\times 20.5-\mathrm{cm}$-high endboxes, each with aluminum walls, a Plexiglas top, and a shock grid floor. The grid-floor geometry was identical to that used in Experiments 1 and 2. The endboxes had aluminum guillotine doors and could be interchanged.

Shock was provided by one of four sources: a 35-kohm, 150-kohm, or 600-kohm fixed-impedance ac source or a $500-\mathrm{V}$ constant-current ac source (Masterson, in press; Masterson \& Campbell, 1972). For our present purposes, the most important aspect of these sources is their progression in terms of source impedance: $35 \mathrm{kohm}, 150 \mathrm{kohm}, 600 \mathrm{kohm}$, and, with highest impedance values of all, the $500-\mathrm{V}$ source for which the impedance falls in the megohm range at low current inten- 
sities). The higher the impedance, the greater is the capacity of the source to maintain current flow through the high resistances characteristic of minimal paw contact. Hence, the sequence of sources listed above represents a progression in terms of the sources' capacity to produce transient current-density peaks.

The grid polarity scrambler was the same as that used in Experiments 1 and 2.

Procedure. Each trial began with the simultaneous opening of the startbox door and the onset of a particular intensity of shock. The rat could traverse the alley to reach a shock-free goalbox. If the rat did not traverse the alley within $30 \mathrm{sec}$ of trial onset, the shock was discontinued and the rat was moved by the experimenter to the goalbox. Following the 30 -sec intertrial interval, the endboxes were spatially interchanged. In particular, the box containing the rat was moved from the goalbox position to the startbox position. Five seconds following this rearrangement, the next trial began.

Shock intensities varied from trial to trial according to a titration schedule (Weiss \& Laties, 1958). For each shock source, 10 logarithmically spaced intensities were selected. If a rat ran to the goalbox within the allotted 30 -sec period, the next lowest shock intensity was used on the subsequent trial. However, if a rat did not run in the allotted time, the next highest shock intensity was used on the subsequent trial. The resulting sequence of titration intensities oscillates within relatively narrow limits, and the average of these titration intensities provides an estimate of the intensity of transition between LSA suppression and LSA production.

For the $150-k o h m$ fixed-impedance ac source, the 10 titration intensities were $0,30,37,45,55,68,83,100,122$, and $150 \mathrm{~V}$. Equally aversive titration intensities were selected for the other three sources by means of the equal-aversion functions derived by Campbell and Masterson (1969).

Eight rats were run for each source. Each rat received a single, 50-trial session.

\section{Results and Discussion}

Observation of the animals confirmed that the average titration intensity marks the transition between LSA suppression and LSA production. At intensities below their average titration intensities, the animals showed obvious signs of distress, flinching and vocalizing, and yet they preferred being shocked in the startbox to running to the goalbox. There can be no question regarding whether or not the animals knew how to escape the shock, since above-average titration intensities reliably elicited escape responses. Hence, at intensities below the average titration intensity, the animals were discomforted and they knew where to go to get away, and yet they stayed with the shock rather than traverse the runway.

The titration intensities decreased slightly over the first 10 to 20 trials and were asymptotic over Trials 21-50. Hence, the data for the first 20 trials were discarded prior to determining the average titration intensities.

For purposes of data analysis, all shock intensities were converted to equally aversive current intensities from the 500-V constant-current source, using Campbell and Masterson's (1969) equal-aversion functions. The resulting currents were then converted to logarithms. A logarithmic scale was used because JADs between low-intensity shocks are equally spaced on such a scale (Masterson, in press; Masterson \& Campbell, 1972). This suggests that the logarithmic current scale is an interval
Table 1

Escape Titration Thresholds for the 35-kohm, 150-kohm, and 600-kohm Fixed-Impedance ac Sources and the 500.V Constant-Current ac Source

\begin{tabular}{ccc}
\hline & \multicolumn{2}{c}{ Threshold } \\
\cline { 2 - 3 } Shock & Escape & E-A* \\
\hline 35 kohm & $24.8 \mathrm{~V}$ & .077 \\
$150 \mathrm{kohm}$ & $45.0 \mathrm{~V}$ & .102 \\
$600 \mathrm{kohm}$ & $128.0 \mathrm{~V}$ & .117 \\
$500 \mathrm{~V}$ & $.218 \mathrm{~mA}$ & .218 \\
\hline
\end{tabular}

* Escape thresholds (in milliamperes) in equally aversive 500.V source intensities.

scale, at least for closely adjacent values. Hence, arithmetic means should be calculated using the logarithmic current scale. After calculating the means, the resulting averages were converted back to currents via the antilogarithm transformation.

The average titration intensities thus obtained are shown in Table 1. To facilitate comparisons, these thresholds are also presented as equally aversive milliampere intensities for the $500-\mathrm{V}$ source. An analysis of variance performed on the individual rats' titration intensities, expressed as logarithmic currents, was significant $[F(3,28)=8.95, p<.01]$. Newman-Keuls comparisons showed that the $500-\mathrm{V}$ source's average titration intensity was reliably higher than those of the other three sources $(\mathrm{p}<.01)$.

All four average titration intensities fell into the ranking predicted by the hypothesis that rats learn to suppress LSA in order to avoid transient peaks in current density. The biggest differences (and the reliable ones, according to the Newman-Keuls analysis) were between the average titration intensity for the $500-\mathrm{V}$ source and those of the other three sources. This is consistent with the current-density hypothesis, since the $500-\mathrm{V}$ source, but not any of the other sources, displays a sufficiently high degree of current regulation to qualify for the title of "constant-current source." In the range of .1-.2 mA, the $500-\mathrm{V}$ source's series resistance is between 5 and 2.5 megohms, which is considerably larger than the (fixed) series resistances of the other sources. Consequently, the 500-V source should produce considerably larger current-density peaks with minimal paw contacts.

\section{GENERAL DISCUSSION}

At least to superficial appearances, there is a qualitative jump between discomfort on the one hand and pain on the other. Beginning with such classic examples as Masserman (1943) and Solomon, Kamin, and Wynne (1953), studies of aversive motivation have focused primarily on painful intensities of stimulation. In contrast, "discomfort motivation," motivation by merely uncomfortable stimuli, has not received as much attention. 
The present results suggest that footshock is a poor choice for a discomforting stimulus. Uncomfortable intensities of footshock lie in the lower portion of the range of usable intensities, most likely below the point at which the activity-suppression effect drops out (that is, approximately $100 \mathrm{~V}$ for the $150-\mathrm{kohm}$ source and $.35 \mathrm{~mA}$ for the $500-\mathrm{V}$ source). In that case, it may be very difficult to train animals to perform large-scale responses to escape from merely uncomfortable footshock stimuli.

Unfortunately, other discomforting stimuli, such as loud noises, bright lights, heat, and cold, have their own serious drawbacks. Without exception, these stimuli produce sensory adaptation effects that put a large amount of control over aversiveness into the paws of the subject. For example, the longer a rat waits to press a lever to turn off a loud noise, the less aversive the noise becomes, possibly to the point at which the rat no longer minds its presence (Masterson, 1965, 1969). In light of these problems, it is disappointing that electric footshock is likewise (although for a different reason) a poor candidate for studying discomfort motivation.

The possibility remains that alterations in the shockdelivery system might diminish or eliminate the LSAsuppression effect. Different scrambler switching frequencies should be explored. Zener diodes might be used to clamp a source's output voltage, thus curtailing the source's capacity to force current through indefinitely large resistances (Ali \& Reiter, 1977). Another possibility is that discontinuous shock may reduce the suppression effect. For example, D'Amato, Fazzaro, and Etkin (1967) obtained good barpress avoidance performance with $.2 \mathrm{~mA}$ pulsed footshock $(.2 \mathrm{sec}$ on, $2.0 \mathrm{sec}$ off). Perhaps the rats learned to limit their LSAs to the 2 -sec periods between the shock pulses.

\section{REFERENCES}

ALI, J. S., \& RE1TER, L. A self-contained, regulated, burst-firing constant-current ac shock generator. Behavior Research Methods \& Instrumentation, 1977, 9, 326-333.

Campbell, B. A., \& Masterson, F. A. Psychophysics of punishment. In B. A. Campbell \& R. M. Church (Eds.), Punishment and aversive behavior. New York: AppletonCentury-Crofts, 1969.

D'Amato, M. R., Fazzaro, J., \& Etkin, M. Discriminated barpress avoidance maintenance and extinction in rats as a function of shock intensity. Journal of Comparative and Physiological Psychology, 1967, 63, 351-354.

KimbLE, G. A. Shock intensity and avoidance learning. Journal of Comparative and Physiological Psychology, 1955, 48, 281284.

LEVINE, S. UCS intensity and avoidance learning. Journal of Experimental Psychology, 1966, 71, 163-164.

Masserman, J. H. Behavior and neurosis. Chicago: University of Chicago Press, 1943.

MASTERSON, F. A. Equal aversion functions as predictors of instrumental responding. Unpublished doctoral dissertation, Princeton University, 1965.

Masterson, F. A. Escape from noise. Psychological Reports, $1969,24,484-486$.

MAste RSON, F. A. Is termination of a warning signal an effective reward for rats? Journal of Comparative and Physiological Psychology, 1970, 72, 471-475.

Masterson, F. A. Grid and peripheral shock stimulation. In M. M. Patterson \& R. Kesner (Eds.), Electrical stimulation techniques. New York: Academic Press, in press.

Masterson, F. A., \& Campbell, B. A. Techniques of electric shock motivation. In R. D. Myers (Ed.), Methods in psychobiology (Vol. 2). New York: Academic Press, 1972.

Solomon, R. L., Kamin, L. J., \& Wynne, L. C. Traumatic avoidance learning: The outcomes of several extinction procedures with dogs. Journal of Abnormal and Social Psychology, 1953, 48, 291-302.

Weiss, B., \& LAties, V. G. Fractional escape and avoidance on a titration schedule. Science, 1958, 128, 1575-1576.

(Received for publication July 30, 1980; revision accepted February 20, 1981.) 